\title{
Transabdominal Resection of Giant Intrapelvic Schwannoma
}

\author{
Chang-Yong Park, Sang-Hyun Kim \\ Department of Neurosurgery, Ajou University College of Medicine, Suwon, Korea
}

In published series on presacral tumors, $5 \%$ to $15 \%$ of tumors are neurogenic origin. We report a rare and giant intrapelvic schwannoma which may be the biggest tumor ever reported with literature review. A 52-year-old male presented with lower back pain and voiding difficulty for about 3 years ago. Magnetic resonance image (MRI) revealed huge neurogenic tumor $(15.5 \times 9.5 \times 11.0 \mathrm{~cm})$ originated from sacral plexus, especially S2. The patient underwent low anterior abdominal approach by general surgeon. When abdominal cavity was exposed, thinned bladder wall was not differentiated from peritoneum. Primary repair was needed because of injury of bladder wall. Demarcation of tumor was well preserved and tumor was easily separated from the capsule. Subtotal resection of tumor was done. Presacral tumors, irrespective of origin, cause similar symptoms due to their location in the presacral space. The mode of presentation reflects the tumor size, mass effect and presence of infection. These may manifest locally as back pain, rectal pain or neurological defects. Prior to any surgical intervention, information of tumor is important: tumor size, extent of loco-regional dissemination, involvement of the tissue planes between neighboring structures, and the degree of vascular involvement. In operation, adhesion may present surrounding pelvic structure then surgery had to subtotal removal of tumor rather than total removal. In these cases, piecemeal resection of tumor is recommended. We thought that huge size tumor surgery was carefully performed because of important pelvic organ injury that make severe neurologic deficit.

Key Words: Neurilemmoma $\cdot$ Pelvis • Urination disorders

\section{INTRODUCTION}

Pelvic tumors of neurogenic origin are rare and their true incidence is not known. In published series on presacral tumors, $5 \%$ to $15 \%$ of tumors are neurogenic origin ${ }^{3,9)}$. Growth of these tumors is frequently indolent and they cause minimal or ill-defined often remote symptoms from the site of neoplasm. As a consequence, diagnosis is often delayed, tumors may reach considerable size, and they may involve surrounding structures, making their management complex.

Moreover, surgical treatment of these tumors are challenging to achieve complete resection of them without a unexpected injury to urinary system, digestive system, reproductive system and neural structures, which may result in significant morbidities. The size of tumor is one of the main factors which may be related to the incidence of those morbidities. We report a rare and giant intrapelvic schwannoma which may be the biggest tumor ever reported with literature review.

Corresponding author: Sang Hyun Kim Department of Neurosurgery, Ajou University College of Medicine, 164, World Cup-ro, Yeongtong-gu, Suwon 16499, Korea

Tel: +82-219-5235, Fax: +82-31-219-5238

E-mail:shkim709@aumc.ac.kr

\section{CASE REPORT}

A 52-year-old male presented with lower back pain and voiding difficulty for about 3 years ago. Abdominal computed tomography (CT) scan incidentally revealed compressed bladder by pelvic mass and he was transferred to neurosurgery outpatient clinic. Magnetic resonance image (MRI) revealed huge neurogenic tumor $(15.5 \times 9.5 \times 11.0 \mathrm{~cm})$ originated from sacral plexus, especially S2 (Figs. 1-3).

The patient underwent low anterior abdominal approach by general surgeon. When abdominal cavity was exposed, thinned bladder wall was not differentiated from peritoneum. Primary repair was needed because of injury of bladder wall. When
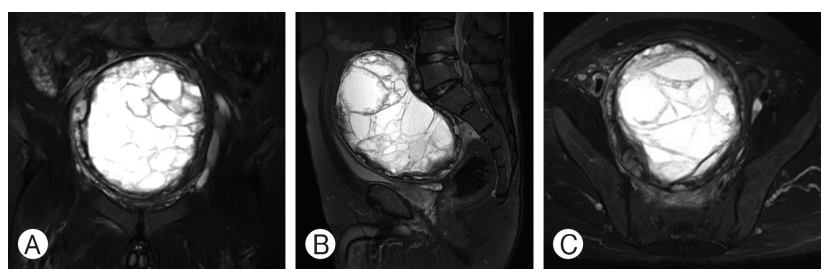

Fig. 1. T2-weighted coronal (A), sagittal (B), axial (C) preoperative tumor image. Magnetic resonance image (MRI) revealed huge neurogenic tumor $(15.5 \times 9.5 \times 11.0 \mathrm{~cm})$ originated from sacral plexus, especially $\mathbf{S}$. 


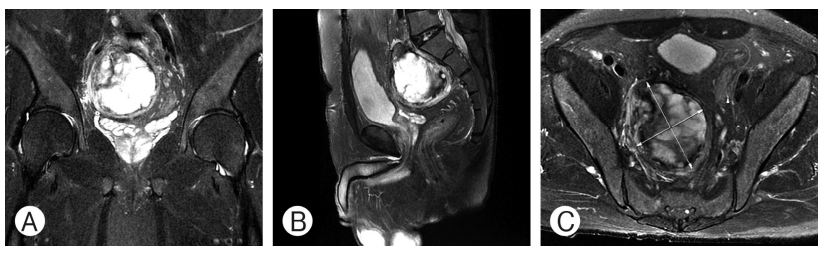

Fig. 2. Fat-suppressed T2-weighted coronal (A), sagittal (B), axial (C) postoperative tumor image. There was remained tumor and capsule on magnetic resonance image in the post-operative 7 months.
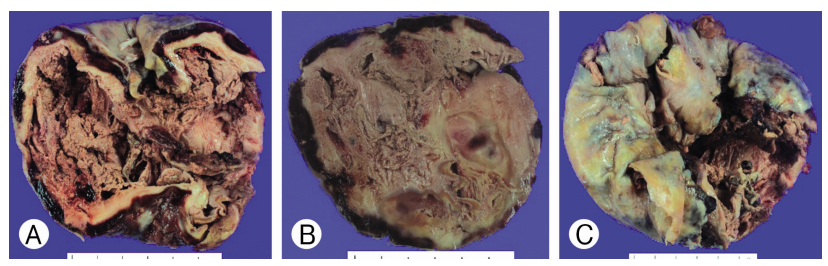

Fig. 3. (A-C) Photograph of the transected specimen showing the schwannoma.

abdominal wall including peritoneum was retracted, the pelvic tumor capsule was revealed. During the operation, while the tumor was separated from the surrounding tissues and vessels with dissection, the sacral nerve roots were preserved as much as possible. Capsule incision was made in a cruciate shape, and then subcapsular dissection was done to make a dissection plane and surgical window, internal decompression of tumor was done. After internal decompression and drainage of dark blood colored cystic fluid, sufficient space for tumor removal could be achieved. Demarcation of tumor was well preserved and tumor was easily separated from the capsule. Subtotal resection of tumor was done, with preserving the capsule of tumor. The capsule was remained and sutured. The closure of abdomen was done by general surgeon. The duration of the operation was approximately $150 \mathrm{~min}$. Bleeding was approximately $500 \mathrm{~mL}$. There was not a blood transfusion during surgery. After surgery, for two days $1,200 \mathrm{~mL}$ transfusions was required.

Foley catheter was indwelled for 2 weeks after the surgery because of bladder injury. The patient was fully recovered without any urologic and neurologic deficit. The specimen was a round well-demarcated excised tumor. The outer surface was relatively smooth. Cut section shows cystic degeneration of the tumor. The degenerated area showed brownish granular material covering cystic tumor. A part of solid area showed yellowish brown cut surface with focal dark reddish hemorrhage portion. Pathology of the tumor was schwannoma.

\section{DISCUSSION}

Presacral tumors, irrespective of origin, cause similar symp- toms due to their location in the presacral space. The mode of presentation reflects the tumor size, mass effect and presence of infection. Since these tumors are typically slow growing, symptoms are often insidious in onset. Although in 26\% to $50 \%$ of cases the tumors are asymptomatic, resulting from compression, displacement or invasion of pelvic structures, viscera and nerves ${ }^{11,13,19)}$. These may manifest locally as back pain, rectal pain or neurological defects ${ }^{11,13)}$. The pain is typically dull and poorly localized. Invasion of the sacral plexus may generate pain in the legs or buttocks. Urinary and fecal incontinence may follow involvement of the pelvic nerve. Infection of the tumor may result in an abscess, draining sinus or fistulous tract in the para-sacrococcygeal, perirectal or perianal spaces. A history of recurrent regional sepsis or fistulation should raise suspicion of an underlying lesion. Obstruction of the pelvic outlet may result in an altered bowel habit. Complications during pregnancy have also been described ${ }^{9,14)}$.

Schwannoma is a tumor of the nerve sheath of schwann cells and may arise along the course of any myelinated nerve, with the vestibulocochlear nerve being the most frequent site. These tumors are usually encapsulated, present as a solitary mass and have a benign course ${ }^{17}$. These tumors can vary from firm, solid masses to fluctuant cysts. The occurrence of a retroperitoneal schwannoma is rare, comprising only $1 \%$ to $3 \%$ of all schwannomas ${ }^{5)}$ and only $1 \%$ of all retroperitoneal tumors ${ }^{7}$. Retroperitoneal schwannomas occur most commonly in patients between forty and sixty years of age, with a male:female ratio of 2:3. Because they are usually slow growing and asymptomatic, retroperitoneal schwannomas are often found incidentally, as in the present case. Although patients with a retroperitoneal schwannoma are usually asymptomatic, some present with vague and nonspecific abdominal or back pain.

Laboratory data for schwannoma are generally not remarkable or contributory to its diagnosis. Histologically, schwannomas consist of compact cellular lesions (Antoni type A tissue) and loose, hypocellular, myxoid lesions with microcystic spaces (Antoni type B tissue). In addition, almost all schwannomas show intense immunohistochemical staining for S-100 protein, confirming the neuroectodermal origin of the tumor cells ${ }^{16)}$.

Prior to any surgical intervention, information of tumor is important: tumor size, extent of loco-regional dissemination, involvement of the tissue planes between neighboring structures, and the degree of vascular involvement. Excision is attainable through trans-sacral, abdominal, combined abdominal-sacral, trans-rectal or trans-vaginal routes.

The choice of the surgical approach in patients with a suspected sacral schwannoma is dependent upon the degree of both sacral destruction and intrapelvic extension which are in direct relationship with tumor size. Most surgeons have recommended an aggressive approach with the aim of achiev- 
ing a complete resection even if it results in the loss of bowel or bladder control. An anterior abdominal or retroperitoneal approach is usually required to protect the vascular plexus and intrapelvic organs and to liberate the tumor ${ }^{15)}$. A combined abdominosacral approach allows an easier resection of the intrapelvic tumor components and carries low risk of injury to the pelvic vasculature, whereas the posterior approach allows a better exposure of the nerve roots and the cauda equina $^{4)}$.

The majority of published series have focused on open surgery, but a small number of more recent reports describe the laparoscopic approach ${ }^{2,10,12)}$. Whichever method is favored, surgical treatment for presacral tumors may have a risk of complication ocurrence. Specifically, in the case of bulky and locally advanced tumors, making excision on tumor can be hazardous, in particular if the tumor is adherent to the presacral venous plexus. Establishing hemostasis may pose considerable difficulties. Accordingly, several methods of controlling presacral bleeding have now been described, including the use of thumbtacks, sacral sponges, endoscopic stapling devices and muscle fragment welding ${ }^{1,6,8,18)}$. Hence, surgery should be attempted with full precautions and the fully informed consent of the patient. Presacral tumor often has internal bleeding when tumor is huge size because of slowly growing. Therefore prior to removal of huge mass, internal decompression must be performed. In case of a tumor presenting in pelvic cavity, they may involve surrounding structures bladder, rectum, reproductive organs. Total removal of tumor may cause injury of surrounding organ that make severe neurologic deficit. So in operation, adhesion may present surrounding pelvic structure then surgery had to subtotal removal of tumor rather than total removal. In these cases, piecemeal resection of tumor is recommended.

\section{CONCLUSION}

Huge size tumor has different nature with small size tumor. Bladder, peritoneum, kidney and sigmoid colon's position was different from normal anatomy. In our case bladder injury was occurred in operation. So we thought that huge size tumor surgery was carefully performed because of important pelvic organ injury that make severe neurologic deficit.

\section{REFERENCES}

1. Arnaud JP, Tuech JJ, Pessaux P: Management of presacral venous bleeding with the use of thumbtacks. Dig Surg 17:651-652, 2000
2. Bax NM, van der Zee DC: The laparoscopic approach to sacrococcygeal teratomas. Surg Endosc 18:128-130, 2004

3. Cody HS, 3rd, Marcove RC, Quan SH: Malignant retrorectal tumors: 28 years' experience at Memorial Sloan-Kettering Cancer Center. Dis Colon Rectum 24:501-506, 1981

4. Domínguez J, Lobato RD, Ramos A, Rivas JJ, G?mez PA, Castro S: Giant intrasacral schwannomas: report of six cases. Acta Neurochir (Wien) 139:954-959; discussion 959-960, 1997

5. Gubbay AD, Moschilla G, Gray BN, Thompson I: Retroperitoneal schwannoma: a case series and review. Aust N Z J Surg 65:197-200, 1995

6. Harrison JL, Hooks VH, Pearl RK, Cheape JD, Lawrence MA, Orsay CP, et al.: Muscle fragment welding for control of massive presacral bleeding during rectal mobilization: a review of eight cases. Dis Colon Rectum 46:1115-1117, 2003

7. Hayasaka K, Tanaka Y, Soeda S, Huppert P, Claussen CD: MR findings in primary retroperitoneal schwannoma. Acta Radiol 40:78-82, 1999

8. Hill AD, Menzies-Gow N, Darzi A: Methods of controlling presacral bleeding. J Am Coll Surg 178:183-184, 1994

9. Jao SW, Beart RW, Jr., Spencer RJ, Reiman HM, Ilstrup DM: Retrorectal tumors. Mayo Clinic experience, 1960-1979. Dis Colon Rectum 28:644-652, 1985

10. Köhler C, Kühne-Heid R, Klemm P, Tozzi R, Schneider A: Resection of presacral ganglioneurofibroma by laparoscopy. Surg Endosc 17:1499, 2003

11. Lev-Chelouche D, Gutman M, Goldman G, Even-Sapir E, Meller I, Issakov J, et al.: Presacral tumors: a practical classification and treatment of a unique and heterogeneous group of diseases. Surgery 133:473-478, 2003

12. Melvin WS: Laparoscopic resection of a pelvic schwannoma. Surg Laparosc Endosc 6:489-491, 1996

13. Singer MA, Cintron JR, Martz JE, Schoetz DJ, Abcarian H: Retrorectal cyst: a rare tumor frequently misdiagnosed. J Am Coll Surg 196:880-886, 2003

14. Sobrado CW, Mester M, Simonsen OS, Justo CR, deAbreu JN, Habr-Gama A: Retrorectal tumors complicating pregnancy. Report of two cases. Dis Colon Rectum 39:1176-1179, 1996

15. Togral G, Arikan M, Hasturk AE, Gungor S: Incidentally diagnosed giant invasive sacral schwannoma. Its clinical features and surgical management without stability. Neurosciences (Riyadh) 19:224-228, 2014

16. Tortorelli AP, Rosa F, Papa V, Rotondi F, Sanchez AM, Bossola $\mathrm{M}$, et al.: Retroperitoneal schwannomas: diagnostic and therapeutic implications. Tumori 93:312-315, 2007

17. Ugokwe K, Nathoo N, Prayson R, Barnett GH: Trigeminal nerve schwannoma with ancient change. Case report and review of the literature. J Neurosurg 102:1163-1165, 2005

18. van der Vurst TJ, Bodegom ME, Rakic S: Tamponade of presacral hemorrhage with hemostatic sponges fixed to the sacrum with endoscopic helical tackers: report of two cases. Dis Colon Rectum 47:1550-1553, 2004

19. Wolpert A, Beer-Gabel M, Lifschitz O, Zbar AP: The management of presacral masses in the adult. Tech Coloproctol 6:43-49, 2002 